\title{
Estilos Interactivos de Educadoras do Ensino Especial em Contexto de Educação-de-Infância ${ }^{1}$
}

\author{
Catarina Grande ${ }^{2}$ \\ Ana Isabel Pinto \\ Universidade do Porto, Portugal
}

\begin{abstract}
RESUMO - Este estudo pretendeu caracterizar os estilos interactivos das educadoras do Ensino Especial ao se relacionarem com crianças com Necessidades Educativas Especiais (NEE) integradas em creches/jardins-de-infância do Porto. Participaram 50 educadoras e 50 crianças. Os comportamentos interactivos foram avaliados utilizando a Escala de Avaliação dos Estilos de Ensino. O envolvimento das crianças foi codificado por meio do EQUAL-III. A análise de clusters identificou dois subgrupos: (i) educadoras que utilizam mais frequentemente comportamentos directivos; (ii) educadoras nas quais predominam comportamentos elaborativos e responsivos. Os subgrupos distinguiram-se em características de qualidade estrutural da sala, da educadora e do envolvimento da criança. As crianças com NEE parecem se beneficiar de interacções baixas em directividade. Interacções elaborativas-responsivas tendem a promover níveis mais sofisticados de envolvimento, pelo que são recomendadas.
\end{abstract}

Palavras-chave: interações educador-criança; necessidades educativas especiais; creche/jardim-de-infância; intervenção precoce.

\section{Special Education Teachers' Interactive Styles in Early Education}

\begin{abstract}
This study intended to characterize special education teachers' interactive styles while interacting with children with disabilities, in day care/preschool contexts in Porto. Fifty special education teachers and 50 children with disabilities participated in the study. Interactive behaviours were rated based on the Teaching Styles Rating Scale. Child engagement was coded by means of the E-QUAL III. Using cluster analysis, two subgroups of teachers were identified: (i) teachers using more frequently directive behaviours; (ii) teachers with predominance of elaborative and responsive behaviours. Subgroups differences were found for classroom structural quality, teachers' characteristics and children's observed engagement. Children with disabilities seem to benefit from low directive interactions. Elaborative-responsive teacher's interactions tend to promote more sophisticated levels of children's engagement, and are thus recommended.
\end{abstract}

Keywords: teacher-child interactions; special education needs; day care/child care centers; early childhood intervention.

A qualidade dos contextos de educação de infância é, em grande parte, determinada pelas interacções que ocorrem, nesses contextos, entre os educadores e as crianças (de Kruif, McWilliam, Ridley \& Wakely, 2000). A National Association for Education of Young Children - NAEYC (1997) enuncia orientações sobre práticas adequadas para trabalhar com crianças e advoga que os melhores ambientes são os que permitem que a criança tenha um papel activo durante as suas interacções com pares, adultos e objectos (Bredekamp, 1987; Bredekamp \& Rosegrant, 1996). A NAEYC define ainda normas para as práticas desenvolvimentalmente ade-

1 Este estudo faz parte do Projeto de Doutoramento intitulado "Estudo do Impacto das Interacções Educadora-Criança no Envolvimento das Crianças com Necessidades Educativas Especiais em Contexto de Creche e de Jardim-de-Infância", desenvolvido na Faculdade de Psicologia e de Ciências da Educação da Universidade do Porto e financiado pela Fundação para a Ciência e Tecnologia (BD/21605/2005). Agradecemos às educadoras e às crianças observadas e a todas as instituições que permitiram a realização do estudo.

2 Endereço para correspondência: Faculdade de Psicologia e de Ciências da Educação, Universidade do Porto. Rua do Dr. Manuel Pereira da Silva, 4200-392. Porto, Portugal. Fax: +351 226079 725; Fone: +351 226079 700.E-mail: cgrande@fpce.up.pt. quadas, incidindo em quatro áreas específicas: (1) currículo; (2) interacções adulto-criança; (3) relações entre a família e o programa; e (4) avaliação do desenvolvimento da criança.

Relativamente às interacções adulto-criança, Bredekamp (1987) sublinha que a adequação desenvolvimental está relacionada com certos comportamentos do adulto: (a) fornecer respostas rápidas e directas às necessidades, desejos e mensagens das crianças, sendo essas respostas adaptadas aos diferentes estilos e capacidades das crianças; (b) possibilitar muitas e variadas oportunidades para as crianças comunicarem; (c) facilitar o sucesso da criança ao completar as tarefas, fornecendo-lhe suporte, atenção focalizada, proximidade física e encorajamento verbal; (d) conhecer e desenvolver técnicas apropriadas para a redução do estresse; (e) aceitar e confortar a criança, facilitando o desenvolvimento da sua auto-estima; (f) favorecer o desenvolvimento do autocontrole da criança; e (g) aumentar as oportunidades para a criança adquirir competências, por meio de planificação adequada. Desse modo, a NAEYC enfatiza a importância de interacções responsivas e sensíveis que facilitem o jogo da criança e orientem o seu desenvolvimento socioemocional, sendo 
consideradas desenvolvimentalmente adequadas quando os educadores: (a) respondem de forma contingente, directa e calorosa às crianças; (b) fornecem uma variedade de oportunidades para participar numa comunicação com dois sentidos; e (c) identificam e elaboram os sentimentos, interesses e actividades da criança (Bredekamp, 1987).

Os estudos realizados acerca do efeito das interacções educador-criança no comportamento e nos resultados desenvolvimentais da criança investigaram a quantidade e a qualidade das interacções, tendo sido relatado que interacções mais frequentes e mais longas estão relacionadas com vinculação mais segura e que quando as crianças se sentem seguras, têm maior probabilidade de explorar o ambiente e, desse modo, aumentar as oportunidades de aprendizagem (de Kruif, McWilliam \& Ridley, 2001b). No entanto, a quantidade de tempo que os educadores passam a interagir com as crianças nas suas salas de educação de infância é, surpreendentemente, baixa. Esse resultado é confirmado por investigações referidas por de Kruif e cols., as quais indicam que os educadores de crianças com e sem incapacidades passam não mais do que $38 \%$ do seu tempo a prestar apoio a actividades de jogo livre.

A qualidade das interacções dos educadores com as crianças tem sido realçada como sendo ainda mais relevante. As investigações têm demonstrado que os educadores que se envolvem em interacções responsivas e sensíveis têm maior probabilidade de desenvolver uma relação segura, essencial para promover a segurança das crianças. Diversos estudos referem que crianças que têm educadores menos directivos, menos ríspidos e menos desligados, desenvolvem interacções mais positivas, são mais sociáveis (Phillips, McCartney \& Scarr, 1990), demonstram níveis mais elevados de desenvolvimento da linguagem e são mais competentes em actividades cognitivas (Howes \& Stewart, 1987). Esses resultados sublinham o papel que o educador tem em encorajar as crianças a envolverem-se em comportamentos mais sofisticados e em interacções verbais com o seu ambiente (de Kruif \& cols., 2001b), embora não forneçam muita informação sobre a natureza e a complexidade das interacções. Nesse sentido, foram desenvolvidos estudos com o objectivo de investigar a especificidade dos comportamentos interactivos dos educadores em salas de educação de infância, analisando com que medida variações nesses comportamentos interactivos se relacionavam com o envolvimento, bem como com outros resultados desenvolvimentais das crianças (de Kruif, Zully, McWilliam, Scarborough \& Sloper, 1998; de Kruif \& cols., 2000).

Em 1998, de Kruif e cols. realizaram um estudo de análise qualitativa para investigar a natureza dos estilos interactivos em 10 educadores e o seu efeito no envolvimento de 63 crianças com e sem incapacidades. Os autores concluíram que as interacções que os educadores estabeleciam com as crianças ocorriam de uma forma que era altamente previsível ao longo do tempo, podendo os seus comportamentos interactivos ser classificados nas seguintes categorias: (a) Directivos-Responsivos (DR); (b) Directivos-Não Responsivos (DNR); e (c) Não DirectivosResponsivos (NDR). Nesse estudo, os autores consideraram Directividade e Responsividade como duas dimensões constituindo contínuos separados e não como dois extremos de um mesmo contínuo. Esse estudo revelou, igualmente, que os estilos interactivos dos educadores se relacionavam com a quantidade de tempo que as crianças passavam a interagir de forma adequada, a nível desenvolvimental e contextual, com adultos, pares ou materiais, podendo essa interacção assumir diferentes níveis de competência cognitiva. Desse modo, em salas com educadores Directivos-Responsivos (DR), as crianças: (1) revelavam níveis mais sofisticados de envolvimento durante as suas interacções (e.g., testar hipóteses, resolver ou testar problemas); (2) tinham interacções seguras e recíprocas, sendo apreciadas por outras crianças; e (3) mantinham-se envolvidas nas actividades por longos períodos de tempo.

Com relação aos educadores Directivos-Não Responsivos (DNR), o elevado controle por parte do adulto relativamente às actividades das crianças influenciava $o$ seu envolvimento. Nessas salas verificou-se que: (1) as expectativas dos educadores relacionados ao envolvimento adequado por parte das crianças baseavam-se num leque muito limitado de comportamentos, sendo que não incluíam adequações nas actividades quando estas revelavam ser demasiadamente desafiantes, limitando, assim, o número de crianças que participavam nas actividades; (2) as actividades forneciam poucas oportunidades às crianças que eram capazes de se envolver de forma independente com os materiais e, assim, dirigir a sua própria actividade; (3) o elevado controle por parte do educador durante as actividades não permitia às crianças o desenvolvimento dos tópicos por elas iniciados. Em salas orientadas por educadores DNR, as crianças estavam menos tempo envolvidas e rapidamente perdiam o interesse e abandonavam as actividades. As crianças eram introduzidas nas actividades seguindo instruções e completavam as actividades de acordo com a instrução do educador, passavam grande parte do tempo à espera de materiais adicionais e de instruções ou permaneciam atentas às demonstrações do educador (de Kruif \& cols., 1998).

Por sua vez, os educadores Não Directivos-Responsivos (NDR) mantinham o envolvimento das crianças nas actividades por meio de elaborações com base nos interesses das crianças, utilizando elogios e encorajamentos e incentivando o seu esforço para participar. Frequentemente, as crianças iniciavam as conversações com os educadores e colocavam questões; eram capazes de se envolver nas actividades, sendo-lhes fornecida oportunidades para se envolverem de forma independente. Essas oportunidades fornecidas à criança para dirigir as actividades, bem como a disponibilidade do educador para ajudar e para expandir as actividades com base nos interesses da criança, resultando em maior envolvimento por parte desta, independentemente do seu estatuto desenvolvimental. Com educadores NDR, as crianças passavam mais tempo envolvidas em actividades e em jogo independente com materiais e com os pares. Os resultados dessa investigação indicam que os estilos de ensino têm efeitos relevantes no envolvimento observado na criança em contexto de educação de infância. Os autores sugerem que diferentes combinações de Responsividade e de Directividade podem ser necessárias para assegurar que todas as crianças do grupo estejam envolvidas de forma adequada (de Kruif \& cols., 1998). 
Em outro estudo sobre a classificação dos comportamentos interactivos de educadores em contextos de educação de infância, de Kruif e cols. (2000) identificaram quatro clusters, com base na Teaching Styles Rating Scale (TSRS) desenvolvida por McWilliam, Scarborough, Bagby e Sweeney (1998): Cluster 1: Educadores Médios - os educadores desse grupo caracterizavam-se por resultados médios em todos os comportamentos; Cluster 2: Educadores Elaborativos - os educadores caracterizavam-se por valores elevados em comportamentos elaborativos e valores baixos em comportamentos de redireccionamento; Cluster 3: Educadores Controladores - os educadores apresentavam cotações elevadas em comportamentos de redireccionamento e cotações baixas em todos os outros comportamentos interactivos; e Cluster 4: Educadores Não-elaborativos - os educadores caracterizavam-se por cotações elevadas em comportamentos não elaborativos. Foram encontradas diferenças entre os clusters em medidas de: (a) sensibilidade dos educadores; (b) qualidade do ambiente; e (c) envolvimento do grupo. As diferenças verificadas entre os quatro clusters no envolvimento de grupo sublinham a relação entre os comportamentos de interacção dos educadores e o que as crianças realizam nas salas de educação de infância. Desse modo, de Kruif e cols. verificaram que nas salas com educadores Controladores (Cluster 3) era menor a percentagem de crianças que permaneciam activamente envolvidas, quando comparadas com as salas de educadores definidos como Médios, Elaborativos e Não-elaborativos. Relativamente ao nível de educação formal dos educadores, os autores verificaram que essa variável justificava parte das diferenças nos comportamentos de interacção, sendo que os educadores Controladores tendiam a ser menos sensíveis e a ter menos anos de educação formal, resultados que são consistentes com os de outros estudos (e.g., Arnett, 1998).

Em Portugal, são escassos os estudos sobre padrões interactivos das educadoras em contextos de educação de infância, e do seu efeito no envolvimento das crianças. $\mathrm{Na}$ Área Metropolitana do Porto, foi realizado um estudo de caracterização de padrões interactivos dos educadores em contexto de creche (Pinto, 2006). A autora identificou dois estilos interactivos de educadores: (1) Educadores Directivos - Elaborativos, caracterizados por obterem valores mais baixos no comportamento Redirecciona e por valores mais elevados em todos os outros seis comportamentos de ensino (Introduz, Elabora, Segue, Informa, Reconhece e Elogia), bem como na dimensão Afecto; (2) Educadores Directivos - Não Contingentes, caracterizados por valores extremamente elevados no comportamento Redirecciona e cotações baixas em todos os outros comportamentos, bem como na dimensão Afecto. Nesse estudo, verificou-se que esses estilos interactivos se distinguiam relativamente: (a) a características de estrutura da sala; (b) a características do educador; e (c) ao envolvimento das crianças. Assim, os educadores Directivos - Não Contingentes tinham cotações significativamente mais baixas na qualidade global da sala e relativamente ao envolvimento de grupo, sendo que nas salas desses educadores uma percentagem menor de crianças estava activamente envolvida. Relativamente às características de estrutura da sala, Pinto não encontrou diferenças entre os dois clusters de estilos interactivos dos educadores relativamente ao número de adultos na sala, ao tamanho do grupo ou ao rácio ${ }^{3}$ educador:criança. Em relação às características de estrutura do educador, a autora verificou que os dois grupos de educadores diferem no tempo para planificação e para trabalho directo, no salário, no nível de educação, na experiência e na idade: os educadores designados como Directivos - Elaborativos tinham menos tempo de trabalho directo e mais tempo para planificação, tinham salários mais elevados, mais anos de educação formal, menos anos de experiência em creche e eram mais jovens. Relativamente ao envolvimento individual das crianças, Pinto (2006) verificou, ainda, que nas salas com educadores Directivos - Elaborativos, as crianças passavam menores percentagens de tempo em envolvimento não sofisticado e não envolvidas.

Com o objectivo de estudar o efeito de diferentes estilos interactivos de educadores no envolvimento de crianças com incapacidade em idade pré-escolar durante interacções diádicas em actividades de jogo livre e actividades orientadas, Mahoney e Wheeden (1999) verificaram existir uma relação causal entre duas dimensões do estilo interactivo dos educadores e a participação das crianças durante a interacção: (a) a Directividade encorajava as crianças a tornarem-se mais envolvidas na interacção com o educador; (b) a Responsividade encorajava as crianças a iniciar comportamentos sociais e não sociais. Os autores consideram, desse modo, que essas duas dimensões de interacção educativa se complementam. Quando os educadores utilizavam um estilo de interacção caracterizado por elevada Directividade e baixa Responsividade, as crianças tinham maior probabilidade de permanecerem atentas ao educador do que de se envolverem em jogo solitário. Pelo contrário, quando os educadores tinham estilos altamente Responsivos e baixa Directividade, as crianças tinham maior probabilidade de iniciar actividades escolhidas por si e menor probabilidade de incluir o educador nas suas interacções. Os autores concluíram que, embora níveis moderados de Directividade fossem necessários para encorajar a criança a interagir com o adulto, os resultados encontrados indicam que são os elementos Responsivos do estilo do educador que promovem a atenção das crianças relativamente à actividade. Verificaram ainda que a $\mathrm{Di}$ rectividade dos educadores reduzia os comportamentos de iniciativa da criança, dado que, quanto mais frequentemente a criança se envolve em actividades seleccionadas pelos educadores, menos oportunidades tem para iniciar actividades e para realizar comportamentos escolhidos por si. Quanto à Responsividade, Mahoney e Wheeden verificaram que essa dimensão está positivamente associada às iniciativas da criança, na medida que educadores muito responsivos têm tendência para se implicar em interacções que encorajam as crianças a continuar as actividades que seleccionaram por livre iniciativa. De acordo com os autores, as crianças com incapacidades, quando interagem com adultos responsivos, apoiantes e relativamente não directivos, são capazes de se envolver tanto em activi-

3 Por rácio educador: criança entenda-se a proporção de adultos para o total de crianças na sala de actividades (e.g., um rácio de 1:8, significa que, para essa sala existe 1 adulto para 8 crianças). 
dades de jogo desenvolvimentalmente adequadas por iniciativa própria, como em iniciar comportamentos com significado e relevantes em termos desenvolvimentais. Os resultados apresentados indicam que, se a aprendizagem ocorre como resultado do envolvimento da criança nas rotinas, uma elevada Directividade por parte do educador pode evitar que a criança se envolva em comportamentos desenvolvimentalmente relevantes. Por outro lado, embora a aquisição de competências de níveis de realização superior por parte da criança implicasse a sua participação em actividades estruturadas, os resultados encontrados nesse estudo sugerem que a Responsividade e a implicação social do educador, dimensões opostas à Directividade, são fundamentais para promover a atenção da criança em actividades seleccionadas pelo educador. As crianças com incapacidade se beneficiam mais de práticas instrutivas baixas em Directividade, uma vez que estas apoiam e encorajam processos de aprendizagem construtivos, tais como a exploração, persistência, prática e resolução de problemas. Esse estudo vem salientar a importância de se proporcionar às crianças com incapacidades a oportunidade para participar em actividades orientadas e em interacções que sejam responsivas aos seus interesses individuais e às suas capacidades.

Assim, os estudos têm referido a importância de considerar a Directividade e a Responsividade como duas dimensões separadas, realçando que são desejáveis diferentes combinações dessas dimensões interactivas em função das situações e das características das crianças. Tem sido igualmente constatado que, embora seja desejável que os educadores adaptem os seus comportamentos à especificidade do contexto interactivo, esses educadores tendem a assumir um estilo que é predominante e que constitui um padrão interactivo na sua relação com as crianças.

O objectivo do presente estudo foi caracterizar os comportamentos interactivos e identificar estilos interactivos dos educadores do Ensino Especial durante a sua interacção com crianças com NEE integradas em creches e jardinsde-infância da Área Metropolitana do Porto. Com base nesse racional teórico esperava-se que os educadores do Ensino Especial, à semelhança dos resultados encontrados com educadores do Ensino Regular, revelassem padrões interactivos na sua relação com as crianças, permitindo incluí-las em grupos caracterizáveis por estilos distintos de comportamentos interactivos durante o apoio educativo. Assim, as seguintes questões de investigação foram colocadas: (1) Em que medida é possível identificar grupos de educadores do Ensino Especial com base na caracterização dos seus comportamentos interactivos em situações de apoio educativo?; (2) Em que medida esses grupos variam em função de variáveis de qualidade de estrutura, nomeadamente: (a) características de qualidade da sala (número de adultos, tamanho do grupo e rácio educador:criança); (b) características de qualidade relativas ao educador (idade, anos de educação formal, anos de serviço em educação de infância e anos de serviço no ensino especial)?; (3) Em que medida o envolvimento individual de crianças com NEE, observado em contextos de educação de infância inclusivos, varia em função dos estilos interactivos dos seus educadores do Ensino Especial?.

\section{Método}

\section{Participantes}

Participaram no presente estudo 50 educadores do Ensino Especial, bem como as 50 crianças com incapacidades apoiadas por esses educadores em contextos de creche e jardimde-infância inclusivos da Área Metropolitana do Porto.

Foi requerido à Direcção Regional de Educação do Norte uma listagem dos agrupamentos das crianças com NEE integradas em contexto de creche e de jardim-de-infância e solicitou-se a colaboração dos Conselhos Executivos dos Agrupamentos de Escola para procederem a divulgação deste estudo junto dos educadores de Ensino Especial, convidandoos a participar. Posteriormente, foi-nos fornecida a listagem dos educadores que aceitaram participar, sendo estabelecido um contacto pessoal com a finalidade de explicar os objectivos do estudo. Por fim, foi solicitada e formalizada a colaboração da instituição e a autorização da família.

A Tabela 1 apresenta as características demográficas dos educadores participantes. Todos os educadores eram do sexo feminino pelo que, doravante, serão designadas por educadoras.

\section{Medidas}

As seguintes variáveis de classificação foram consideradas no presente estudo:

(1) Comportamentos de ensino das educadoras do Ensino Especial. A classificação dos comportamentos específicos de interacção e das características afectivas das educadoras foi realizada com base na Teaching Styles Rating Scale (TSRS; McWilliam \& cols., 1998). Neste estudo foi utilizada a versão portuguesa da escala (Escala de Avaliação dos Estilos de Ensino - EAEE), traduzida no âmbito do projecto de investigação - A qualidade das interacções da criança em contexto familiar e creche e o seu impacto no desenvolvimento socio-cognitivo da criança -, desenvolvido pelo Centro de Psicologia da Universidade do Porto e financiado pela Fundação para a Ciência e Tecnologia (Referência POCTI/PSI/35207/2000).

$\mathrm{Na}$ EAEE, os comportamentos de ensino são medidos por meio de sete itens discretos (cf. Tabela 2) e cotados numa escala Likert de sete pontos, com quatro descritores: 1=nunca, 3=ocasionalmente, 5=frequentemente, 7=a maior parte do tempo. Os comportamentos avaliados nessa escala não são mutuamente exclusivos, pelo que vários itens podem ser cotados como ocorrendo a maior parte do tempo. As cotações baseiam-se na observação e devem reflectir a proporção de tempo interactivo passado pela educadora em cada comportamento de interacção.

Em estudos prévios (e.g., de Kruif \& cols., 2000; Pinto, 2006), os sete comportamentos de ensino da EAEE (cf. Tabela 2) foram combinados para constituir dimensões interactivas. No presente estudo foi utilizada apenas uma dessas dimensões, Comportamentos Elaborativos, constituída pela média dos comportamentos Elabora e Segue, cujos dados apresentam uma consistência interna aceitável $(\alpha=.87)$ para que possa ser considerada como uma variável em análises posteriores. 
Tabela 1. Características demográficas das educadoras.

\begin{tabular}{|c|c|c|c|c|c|}
\hline Características das Educadoras do Ensino Especial & $n$ & $\%$ & $M$ & $D P$ & Amplitude \\
\hline \multicolumn{6}{|l|}{ Gênero } \\
\hline Feminino & 50 & 100 & & & \\
\hline Idade & & & 44,5 & 5,5 & $33-62$ \\
\hline Anos de educação formal & & & 18,0 & 1,6 & $16-23$ \\
\hline Anos de serviço em Educação de Infância & & & 19,7 & 5,3 & $9-32$ \\
\hline Anos de serviço no ensino especial & & & 9,3 & 8,1 & $0-28$ \\
\hline \multicolumn{6}{|l|}{ Níveis de educação dos educadores } \\
\hline Formação graduada & 50 & & & & \\
\hline Bacharelato & 10 & 20 & & & \\
\hline Licenciatura & 40 & 80 & & & \\
\hline Curso de Formação Especializada & 29 & 58 & & & \\
\hline Licenciatura em Educação de Infância & 11 & 22 & & & \\
\hline Formação pós-graduada & 11 & 22 & & & \\
\hline Pós-graduação & 6 & 12 & & & \\
\hline Mestrado & 5 & 10 & & & \\
\hline \multicolumn{6}{|l|}{ Formação em Intervenção Precoce } \\
\hline Formação Inicial & 13 & 26 & & & \\
\hline Formação Complementar Pontual & 13 & 26 & & & \\
\hline Projecto de Intervenção Precoce & 9 & 18 & & & \\
\hline
\end{tabular}

(2) Características afetivas das educadoras do Ensino Especial. A dimensão relativa às características afectivas da EAEE é avaliada por meio de 14 itens (cf. Tabela 3), cotados numa escala de cinco pontos, com três descritores relativos à frequência ou qualidade do comportamento (pontos 1, 3 e 5). Os descritores diferem de item para item. Em estudos prévios foram encontrados índices elevados de consistência interna dos dados para a dimensão Afecto, permitindo calcular a média desses itens para produzir uma única classificação para essa dimensão. No presente estudo, a consistência interna dos dados relativos à dimensão Afecto foi de $\alpha=.81$, indicando que os itens dessa dimensão podem ser combinados numa nota global.

Os três observadores da equipe de recolha de dados foram treinados na codificação da EAEE com recurso a registros de video e por meio de cotação ao vivo de comportamentos de ensino de educadoras não pertencentes à amostra. Com base nos registros de video, a percentagem de acordo, nos 21 itens da EAEE, variou entre $86 \%$ e $100 \%$, com uma média de $91.7 \%$ (quando consideradas diferenças de um valor entre cotações - acordo "within one"). Foram ainda duplamente cotadas cinco situações de interacção ao vivo com crianças com NEE, não pertencentes à amostra do estudo. Nos 21 itens, a percentagem de acordo ("within one") variou entre $80 \%$ e $100 \%$, com uma média de $96 \%$. O acordo interobser- vadores foi igualmente verificado ao longo do processo de recolha de dados. Vinte e cinco por cento do total das sessões foram duplamente cotadas, num total de 50 sessões. Os valores relativos ao acordo interobservadores ("within one") variaram entre $90 \%$ e $100 \%$ nos sete itens da escala, sendo a percentagem média de acordo para a dimensão do Afecto igual a $92 \%$, e a média global, a $99 \%$. Foi ainda calculado o Coeficiente Weighted Kappa para cada item da EAEE, tendo os valores variado entre 0,30 e 1,0, com uma média de 0,69 , correspondendo a um valor substancial de acordo, segundo Landis e Koch (1977).

As variáveis de validação consideradas foram:

(1) Qualidade de estrutura. Para explorar a validade da classificação dos comportamentos das educadoras foram utilizadas variáveis de qualidade de estrutura relativas às salas de creche e de jardim-de-infância, bem como variáveis relativas à educadora. Estas variáveis de qualidade de estrutura foram obtidas por meio de um questionário elaborado para este estudo, com a finalidade de recolher dados demográficos relativos à educadora e à sala de actividades, e que foi administrado pelo observador responsável por cada sala. Relativamente à educadora, foram consideradas as seguintes características de qualidade: a idade, os anos de educação formal, os anos de serviço e os anos de serviço no Ensino Especial. Relativamente à qualidade de estrutura da sala, foram consideradas 
Tabela 2. Itens da EAEE relativos à dimensão Comportamento de Ensino.

\begin{aligned} & \hline Itens de ensino \multicolumn{1}{c}{ Definição } \\ & \hline Redirecciona Parar o envolvimento actual da criança para a levar a fazer algo diferente. \\ & Introduz Dar uma nova actividade a uma criança que não está envolvida nesse momento. \\ & Elabora $\begin{array}{l}\text { Fornecer às crianças informação ou materiais relacionados com as actividades actuais da criança, mas indo além } \\ \text { do âmbito das especificidades da actividade. }\end{array} \\ &$ Segue Procurar desencadear uma resposta relacionada com as actividades em que a criança está envolvida no momento. \\ & Informa Fornecer informação sem elaborar a partir da actividade actual da criança. \\ & Reconhece Responder às crianças ou suas actividades sem as descrever, desenvolver, ou seguir. \\ & Elogia Aumentar o afecto para transmitir prazer ou admiração pelas crianças. \\ & \hline\end{aligned}

Fonte: TSRS (McWilliam, Scarborough, Bagby, \& Sweeney, 1998); Pinto (2006).

Tabela 3. Itens da EAEE relativos à dimensão Características Afectivas.

\begin{tabular}{|c|c|}
\hline Itens de afecto & Definição \\
\hline Nível de Actividade & $\begin{array}{l}\text { Quantidade de energia que o educador parece estar a despender no sentido de ir ao } \\
\text { encontro das necessidades da criança. }\end{array}$ \\
\hline Expressão Positiva & Transmitir entusiasmo, excitação e felicidade durante as interacções com a criança. \\
\hline Expressão Negativa & Transmitir desprazer ou infelicidade durante as interacções com a criança. \\
\hline Envolvimento Visual & Seguir visualmente as actividades da criança. \\
\hline Contacto Físico & Frequência e amplitude do contacto físico entre o educador e a criança. \\
\hline Responsividade Emocional & Interagir com as crianças de forma calorosa e protectora. \\
\hline Consistência das Interacções & Previsibilidade ou consistência das respostas do educador às crianças. \\
\hline $\begin{array}{r}\text { Responsividade em relação aos interesses } \\
\text { das crianças }\end{array}$ & Interacções do educador baseadas nos interesses das crianças. \\
\hline Directividade em relação à criança & Permitir que a criança dite o ritmo e conteúdo das actividades. \\
\hline Tom & Frequência de comunicação autoritária ou controladora. \\
\hline Inclusão da criança com NEE nas actividades & $\begin{array}{l}\text { Ajudar a criança com NEE a participar totalmente nas actividades de uma forma } \\
\text { consistente. }\end{array}$ \\
\hline Inclusão das outras crianças nas actividades & Solicitar as outras crianças a participar nas actividades de uma forma consistente. \\
\hline $\begin{array}{l}\text { Incidental teaching (ensino por incidentes) } \\
\text { com a criança com NEE }\end{array}$ & Responder e eliciar comportamentos de nível elevado. \\
\hline Adequação desenvolvimental & Adequar as actividades e o conteúdo ao nível desenvolvimental de cada criança. \\
\hline
\end{tabular}

Fonte: TSRS (McWilliam, Scarborough, Bagby, \& Sweeney, 1998); Pinto (2006).

as seguintes características: o número de adultos na sala, o tamanho do grupo e o rácio adulto:criança.

(2) Envolvimento da criança. Para a codificação dos comportamentos de envolvimento das crianças foi utilizado o Sistema de Avaliação da Qualidade do Envolvimento, com base no Engagement Quality Observation System III (E-QUAL III; McWilliam \& de Kruif, 1998). Esse sistema de avaliação foi traduzido e adaptado no âmbito do projecto de investigação já referido anteriormente quando da descrição das Variáveis de Classificação (Ref: POCTI/PSI/35207/2000). O E-QUAL III constitui um procedimento de amostragem por momentos no tempo para a codificação do envolvimento observado de uma criança. McWilliam e de Kruif definiram nove níveis de envolvimento (i.e., persistente, simbólico, codificado, construtivo, diferenciado, atenção focalizada, indiferenciado, atenção ocasional e não envolvido). Estes níveis são exaustivos e mutuamente exclusivos, e estão organizados numa hierarquia de carácter desenvolvimental traduzindo níveis crescentes de competência da criança durante as suas interacções em contextos naturais de vida. Os autores definiram, ainda, quatro tipos de envolvimento (i.e., pares, adultos, objectos e self), igualmente exaustivos e mutuamente exclusivos, relativos ao foco desses comportamentos. Os comportamentos de envolvimento são codificados no final de intervalos de 15 segundos durante sessões de observação de 15 minutos (num total de 60 observações por sessão). Em cada amostra de tempo são registrados dois códigos: o primeiro relativo ao nível de envolvimento e o segundo relativo ao tipo ou foco de envolvimento. Assim, no final de cada intervalo de 15 segundos, o observador (alertado por um sinal sonoro proveniente de um leitor com auricular) codifica o comportamento numa folha de registro. Em cada sessão 
de observação, as frequências de cada código são somadas e o resultado é dividido pelo tempo total da sessão para se obter uma percentagem estimada de tempo de envolvimento. As definições dos nove níveis e tipos de envolvimento são apresentadas na Tabela 4.

Os três observadores da equipe de recolha de dados foram treinados na codificação do envolvimento, com base no E-QUAL III, até ser obtido um acordo interobservadores de $90 \%$ nos níveis e nos tipos de envolvimento. O treino foi realizado com recurso a cassetes de video com situações similares àquelas utilizadas no estudo e permitiu a ampla discussão dos critérios de codificação. $\mathrm{Na}$ fase final do treino de codificação foram igualmente realizadas sessões de observação ao vivo, tendo sido obtido um acordo de $99 \%$. O acordo interobservadores foi ainda verificado no decurso do procedimento de recolha de dados em $25 \%$ do total das sessões de observação (100 sessões de acordo).
Relativamente às características de fidelidade dos dados do E-QUAL III, o acordo interobservadores (\% de acordo nas ocorrências + \% de acordo nas não ocorrências) variou entre 97,3\% e 99\% ( $M=97,9 \%)$ para os níveis de envolvimento e o Coeficiente Kappa variou entre 0,55 e 0,95 ( $M=0,77)$. Nos tipos de envolvimento, o acordo variou entre $96,1 \%$ e $97,4 \%$ $(M=96,9 \%)$ e o Coeficiente Kappa variou entre 0,75 e 0,95 $(M=0,88)$. Estes valores indicam, respectivamente, um nível substancial e um nível quase perfeito de acordo, segundo Landis e Koch (1977).

À semelhança de estudos prévios (Raspa, McWilliam \& Ridley, 2001; Pinto, 2006), alguns níveis de envolvimento foram combinados para dar origem às variáveis envolvimento sofisticado (soma de envolvimento persistente, envolvimento simbólico, envolvimento codificado e envolvimento construtivo) e envolvimento não sofisticado (soma de envolvimento indiferenciado e atenção ocasional). O envolvimento com

Tabela 4. Definições dos níveis e tipos de envolvimento.

Nível

Definição

Persistente Envolve alguma resolução de problemas e algum desafio, frequentemente indicados por uma primeira tentativa falhada. Inclui quer mudança de estratégias quer a utilização da mesma estratégia novamente para resolver o problema ou atingir um objectivo.

Simbólico Envolve o uso de formas convencionais de comportamento como a linguagem, faz-de-conta, linguagem gestual, desenhos etc., que permite à criança reflectir sobre o passado, falar acerca do futuro e construir novas formas de expressão por meio de combinações.

Codificado Envolve o uso de formas convencionais de comportamento que são dependentes do contexto e que dependem de referentes ou estímulos perceptualmente presentes como uma base para suscitar os comportamentos. O comportamento codificado inclui o uso de linguagem.

Construtivo Envolve manipular objectos para criar, fazer ou construir alguma coisa. Inclui juntar objectos em algum tipo de forma espacial e deve incluir alguma indicação de intencionalidade.

Diferenciado Envolve a coordenação e regulação do comportamento que reflecte elaboração e progresso na direcção da convencionalização. Fornece à criança um conjunto de comportamentos que permite a adaptação às exigências e expectativas ambientais, especialmente aos padrões sociais. Inclui interacção activa com o ambiente.

Atenção Focali- Inclui observar ou escutar características no ambiente, pelos menos durante 3 segundos, e deve envolver olhar direc-

zada tamente para uma característica. A atenção focalizada é caracterizada por uma expressão facial séria e um acalmar da actividade motora estranho à tarefa em mão. A criança responde a um conjunto de estímulos mais reduzido.

Indiferenciado A criança interage com o ambiente sem diferenciar o seu comportamento (i.e., de uma forma repetitiva), utilizando comportamentos simples de nível inferior. Um comportamento repetitivo realizado com o objectivo de provocar uma mudança no ambiente ou para manter o "feedback" produzido pelas acções da própria criança.

Atenção Ocasional Implica atenção mais descontraída e mais vasta que a atenção focalizada. A criança presta atenção a uma sequência ou a uma série de coisas numa sequência, ao contrário de estar atenta a um objecto ou pessoa. Inclui a monitorização do ambiente.

Não Envolvido Implica falta de ocupação. Implica a ausência de qualquer um dos outros comportamentos. Inclui esperar, olhar fixamente no vazio, vaguear sem objectivo, chorar, queixar-se, actos agressivos ou destrutivos e comportamento de infracção de regras.

\begin{aligned} \hline Tipos & \multicolumn{1}{c}{ Definição } \\ \hline Pares & Demonstra um dos comportamentos descritos anteriormente relativamente aos pares ou com os pares. \\ Adultos & Demonstra um dos comportamentos descritos anteriormente relativamente a adultos ou com os adultos. \\ Objectos & $\begin{array}{l}\text { Demonstra um dos comportamentos descritos anteriormente relativamente a/com brinquedos, materiais ou } \\ \text { outros aspectos do meio físico. }\end{array}\end{aligned}$

Self Demonstra um dos comportamentos descritos anteriormente relativamente a/ou consigo próprio.

Adaptado de "Child care quality and children's engagement" (Raspa, McWilliam, \& Ridley, 2001) e de "O envolvimento da criança em contexto de creche: os efeitos de características da criança, da qualidade do contexto e das interaç̧ões educativas" (Pinto, 2006). 
pares e o envolvimento com adultos foram igualmente combinados para dar origem à variável envolvimento social.

Tanto as características de qualidade de estrutura relativas à sala e à educadora, como os níveis e tipos de envolvimento da criança foram relacionados com os perfis interactivos das educadoras.

\section{Procedimento}

Após obtenção da autorização das famílias e das instituições onde as crianças estavam integradas foi iniciada a recolha de dados. Na primeira observação, o observador responsável entregou à educadora do Ensino Especial um questionário sobre dados demográficos relativos à criança, um questionário para recolha de dados demográficos da educadora do Ensino Especial e ainda o Índex de Capacidades (Simeonsson \& Bailey, 1991) para descrever as capacidades e as incapacidades das crianças. O horário de observação era combinado previamente com as educadoras de forma a coincidir com momentos de actividades de jogo livre (actividades nas quais a educadora permite a livre escolha de materiais e dá liberdade à criança para iniciar e finalizar a actividade). Cada criança foi observada ao vivo no decurso de oito sessões de 15 minutos em actividades de jogo livre, a decorrer na respectiva sala, em quatro dias diferentes. Em cada dia foram realizadas duas sessões de observação: (a) uma sessão na presença da educadora do Ensino Especial; e (b) outra sessão quando esse profissional não estava presente. Após a observação da criança, iniciava-se um período de 15 minutos de observação dos comportamentos de ensino e das características afectivas da educadora do Ensino Especial, igualmente em situação de actividade de jogo livre. O objectivo desse período de observação foi determinar quais os comportamentos utilizados pela educadora quando esta tinha oportunidades para interagir com as crianças. As cotações, baseadas na proporção de tempo interactivo passado em cada comportamento de interacção, foram assinaladas numa folha de registro específica com base na EAEE.

\section{Análise de dados}

Para determinar a existência de subgrupos de educadoras de acordo com os seus comportamentos de interacção, foi utilizada a técnica de análise de clusters. Essa técnica permite identificar subgrupos homogéneos dentro de uma amostra heterogénea (de Kruif \& cols., 2000). De acordo com o pressuposto de que os educadores de infância diferem entre si na forma como interagem com as crianças e que a forma como cada um deles interage é consistente ao longo do tempo e em diversas situações, o método de análise de clusters foi considerado o método mais adequado para explorar a natureza dos seus perfis de interacção (de Kruif \& cols., 2000; Pinto, 2006). Inicialmente, numa fase de procura de estrutura, foi seleccionado o método hierárquico para explorar o número "natural” de clusters. A medida de semelhança ou distância entre pares de casos utilizada foi o quadrado da distância Euclidiana. Antes de se calcularem os quadrados das distâncias Euclidianas entre cada par de educadoras procedeu-se à estandardização das variáveis da $\operatorname{EAEE~}(M=0$; $D P=1$ ) por estas estarem representadas em escalas diferentes. De forma a identificar subgrupos de educadoras e determinar a solução inicial de clusters foi utilizado, inicialmente, o procedimento de agregação Wards. Posteriormente, para testar a validade interna, foram utilizados três outros procedimentos hierárquicos: (1) ligação entre grupos (between groups linkage); (2) ligação dentro de grupo (within-groups linkage); (3) vizinho mais afastado (furthest neighbour). Este procedimento permitiu comparar os resultados dos diferentes processos de aglomeração e, assim, avaliar a solução inicial. Desse modo, foi possível validar internamente a estrutura de categorização encontrada.

A validade interna foi ainda examinada testando os clusters relativamente às diferenças de médias nas variáveis classificatórias: os sete comportamentos de ensino das educadoras e as variáveis compósitas consideradas, nomeadamente os Comportamentos Elaborativos e a dimensão Afecto. A validade externa foi examinada por meio do cálculo das diferenças de médias entre os clusters em medidas de qualidade de estrutura da sala e das características da educadora. Por fim, foi analisada a relação entre os perfis interactivos das educadoras e os resultados do envolvimento das crianças. Para determinar a magnitude das diferenças entre grupos foi utilizado o coeficiente $d$ de Cohen (1988), uma medida do tamanho do efeito, embora a significância estatística dos dados seja igualmente relatada.

\section{Resultados}

\section{Procedimento de clusterização}

Como potenciais soluções foram determinadas soluções de dois, três e quatro clusters. A análise dos respectivos dendogramas, dos quadros de aglomeração, bem como a comparação entre os resultados obtidos com os diferentes procedimentos de clusterização resultaram numa solução final de dois clusters de educadoras. Para facilitar a interpretação dos dois clusters de comportamentos interactivos das educadoras foram traçados perfis dos clusters (médias estandardizadas para cada variável), apresentados na Figura 1. Na Tabela 5 são apresentadas as médias, desvios-padrão e resultados das diferenças de médias entre os dois clusters nos comportamentos de ensino da EAEE, na dimensão Afecto e na variável compósita Comportamentos Elaborativos.

Cluster 1. As educadoras nesse grupo $(n=10)$ distinguem-se das educadoras pertencentes ao segundo cluster por obterem valores mais elevados em comportamentos directivos: Redirecciona, Introduz e Informa. Esse grupo, quando comparado com o do cluster 2, obtém valores mais baixos nos outros quatro comportamentos de ensino, bem como na dimensão de Afecto. No entanto, embora estas educadoras se caracterizem por tentarem frequentemente parar as crianças no sentido de as levar a fazer algo diferente, elas passam igualmente grande parte do tempo a fazer pedidos às crianças relacionados com aquilo que as crianças estão a fazer (segue), sendo medianamente elaborativas e calorosas nas suas interacções. Essas educadoras distinguem-se das suas 


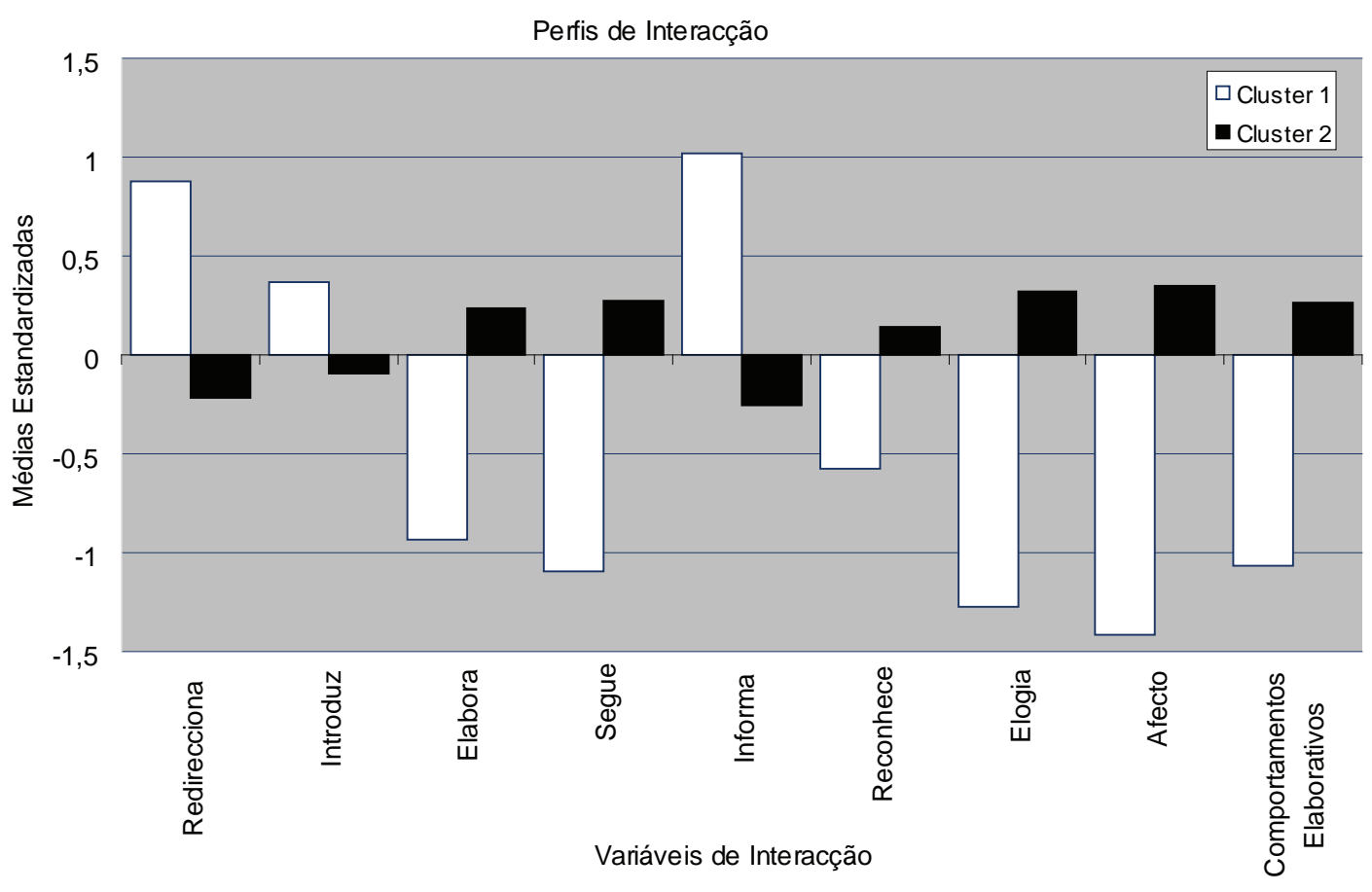

Figura 1. Perfis dos clusters para os Comportamentos de Ensino e Dimensão de Afecto.

colegas do cluster 2 por: (a) introduzirem mais frequentemente as crianças não envolvidas em novas actividades; (b) fornecerem informação sem elaborar a partir da actividade actual da criança; (c) raramente elogiarem as acções da criança. Quando comparadas com as educadoras do outro grupo, relativamente às cotações globais dos Comportamentos Elaborativos, estas educadoras são menos elaborativas e mais directivas. Assim, receberam cotações mais elevadas no comportamento directivo não-contingente Redirecciona e maior cotação nos comportamentos directivos Introduz e Informa. Embora as cotações nesses dois últimos comporta- mentos directivos sejam baixas, elas são mais elevadas do que no outro grupo de educadoras, contribuindo para caracterizar as educadoras do cluster 1 como mais directivas do que as do cluster 2. Deste modo, designamos essas educadoras como Directivas.

Cluster 2. As educadoras neste cluster $(n=40)$ distinguem-se das educadoras do cluster 1 por obterem valores mais elevados nos comportamentos Elabora, Segue, Reconhece, Elogia e na dimensão Afecto, e por cotações mais baixas nos comportamentos Redirecciona, Introduz e Informa (cf. Tabela 5). Esses valores indicam que essas educadoras

Tabela 5. Médias, desvios-padrão e teste $t$ de diferenças de médias para os dois clusters de educadoras nas cotações dos comportamentos da EAEE.

\begin{tabular}{|c|c|c|c|c|c|c|c|}
\hline & \multicolumn{4}{|c|}{ Clusters das Educadoras } & \multirow[b]{3}{*}{$d f$} & \multirow[b]{3}{*}{$t$} & \multirow[b]{3}{*}{$d$} \\
\hline & \multicolumn{2}{|c|}{$\begin{array}{c}\text { Cluster } 1 \\
(n=10)\end{array}$} & \multicolumn{2}{|c|}{$\begin{array}{c}\text { Cluster } 2 \\
(n=40)\end{array}$} & & & \\
\hline & $M$ & $D P$ & $M$ & $D P$ & & & \\
\hline \multicolumn{8}{|l|}{ Variáveis de Classificação } \\
\hline TSRS Redirecciona & 4,35 & 1,45 & 3,00 & 1,01 & 48 & $3,44 * *$ & 1,08 \\
\hline TSRS Introduz & 2,00 & 0,88 & 1,60 & 0,86 & 48 & 1,29 & 0,46 \\
\hline TSRS Elabora & 4,18 & 1,00 & 5,40 & 0,92 & 48 & $-3,69 * *$ & $-1,27$ \\
\hline TSRS Segue & 5,02 & 1,34 & 6,24 & 0,53 & $9,72^{\mathrm{a}}$ & $-2,82 *$ & $-1,20$ \\
\hline TSRS Informa & 1,92 & 0,51 & 1,30 & 0,41 & 48 & $4,13 * * *$ & 1,34 \\
\hline TSRS Reconhece & 3,33 & 0,89 & 4,04 & 1,14 & 48 & $-2,10 *$ & $-0,69$ \\
\hline TSRS Elogia & 2,93 & 0,51 & 5,20 & 1,21 & $35,38^{a}$ & $-9,10 * * *$ & $-2,44$ \\
\hline TSRS Afecto & 4,33 & 0,14 & 4,72 & 0,16 & 48 & $-7,07 * * *$ & $-2,59$ \\
\hline \multicolumn{8}{|l|}{ Variável Compósita } \\
\hline TSRS Comportamentos Elaborativos & 4,60 & 1,15 & 5,82 & 0,67 & 48 & $-4,40 * * *$ & $-1,30$ \\
\hline
\end{tabular}

${ }^{a} \mathrm{O}$ teste $t$ não assume homegeneidade da variância - os graus de liberdade ( $d f$ ) foram modificados ${ }^{*} p<0,05 ; * * p<0,01 ; * * * p<0,001$

$d=$ Média de Cohen para o cálculo do tamanho do efeito (pequeno se $0,20<|d|<0,40$, moderado se $0,40<|d|<0,70$ e grande se $<|d| \geq 0,70$ ) (Cohen, 1988; NICHD ECCRN, 2006). 
frequentemente fornecem às crianças informação ou materiais de forma a elaborar as suas actividades actuais, procuram desencadear respostas relacionadas com as actividades em que a criança está envolvida e elogiam e reconhecem as acções da criança. As cotações mais elevadas na dimensão Afecto e na cotação global Comportamentos Elaborativos indicam que as educadoras pertencentes a este cluster são afectuosas, elaborativas e responsivas, pelo que as designamos Elaborativas.

\section{Validade externa}

Perfis interactivos das educadoras do Ensino Especial: relação com a qualidade de estrutura. A validade externa foi realizada por meio da comparação dos dois clusters relativamente às variáveis de qualidade de estrutura, tanto da sala como da educadora (cf. Tabela 6). Não foram encontradas diferenças entre grupos em função do número de adultos na sala de actividades e do rácio adulto: criança. Embora a diferença em função do tamanho do grupo não seja estatisticamente significativa, verifica-se um efeito entre pequeno e moderado, indicando que o número de crianças é superior em salas com educadoras Directivas (Cluster 1 ). Relativamente às características da educadora, não foram encontradas diferenças em função dos anos de serviço em educação de infância e dos anos de serviço no Ensino Especial. No entanto, verificamos uma diferença grande e estatisticamente significativa entre os dois grupos relativamente aos anos de educação formal e uma diferença moderada, embora não significativa, relativamente à idade das educadoras, indicando que as educadoras Elaborativas (Cluster 2) têm, tendencialmente, mais anos de educação formal e são mais jovens.
Perfis interactivos das educadoras do Ensino Especial: relação com os resultados de envolvimento da criança. Em seguida, foram examinadas as relações entre o envolvimento individual da criança com NEE e os perfis interactivos das suas educadoras do Ensino Especial. Os resultados apresentados na Tabela 7 indicam a existência de uma diferença moderada e estatisticamente significativa no envolvimento não sofisticado, em função do perfil interactivo da educadora. Esse resultado indica que as crianças cujas educadoras são Directivas (Cluster 1) passam mais tempo em envolvimento não sofisticado, o que parece dever-se essencialmente a uma proporção mais elevada de tempo passado por essas crianças em atenção ocasional, isto é, com atenção vaga e monitorizando o ambiente (crianças, adultos e/ou objectos). Verifica-se, ainda, uma diferença, embora de efeito pequeno e não estatisticamente significativa, no nível de envolvimento simbólico, indicando uma tendência para as crianças, que estão em salas com educadoras Elaborativas (Cluster 2), passarem mais tempo em comportamentos de envolvimento mais sofisticado. Para essa diferença contribuem maiores percentagens de tempo que essas crianças despendem com comportamentos de envolvimento simbólico, construtivo e persistente (cf. Tabela 7). Relativamente aos tipos de envolvimento, verificaram-se diferenças moderadas, embora não estatisticamente significativas, no envolvimento com pares e com adultos, indicando que, nas salas com educadoras Elaborativas, as crianças passam mais tempo em interacção com adultos e menos tempo em interacção com os pares. Essa constatação parece indicar que essas educadoras centram a sua intervenção numa interacção essencialmente de carácter diádico adulto-criança, no sentido de solicitar respostas da criança relacionadas com aquilo que ela está a fazer, bem como elaborar as suas actividades.

Tabela 6. Médias, desvios-padrão e teste $t$ de diferenças de médias em variáveis de qualidade de estrutura.

\begin{tabular}{|c|c|c|c|c|c|c|c|}
\hline & \multicolumn{4}{|c|}{ Clusters das Educadoras } & \multirow[b]{3}{*}{$d f$} & \multirow[b]{3}{*}{$t$} & \multirow[b]{3}{*}{$D$} \\
\hline & \multicolumn{2}{|c|}{$\begin{array}{c}\text { Cluster } 1 \\
(n=10)\end{array}$} & \multicolumn{2}{|c|}{$\begin{array}{c}\text { Cluster } 2 \\
(n=40)\end{array}$} & & & \\
\hline & $M$ & $D P$ & $M$ & $D P$ & & & \\
\hline \multicolumn{8}{|l|}{ Características de Estrutura da Sala } \\
\hline Número de adultos & 3,00 & 0,47 & 2,95 & 0,71 & 48 & 0,21 & 0,08 \\
\hline Tamanho do grupo & 21,40 & 5,08 & 19,63 & 3,83 & 48 & 1,23 & 0,39 \\
\hline Rácio & 7,40 & 2,54 & 7,09 & 2,34 & 48 & 0,37 & 0,13 \\
\hline \multicolumn{8}{|l|}{ Características de Estrutura da Educadora } \\
\hline Idade & 46,23 & 3,10 & 44,09 & 5,84 & 48 & 1,12 & 0,46 \\
\hline Anos de educação formal & 17,10 & 0,99 & 18,25 & 1,58 & 48 & $-2,19 *$ & $-0,87$ \\
\hline Anos de serviço - educação de infância & 19,40 & 3,31 & 19,83 & 5,75 & $24,52^{\mathrm{a}}$ & $-0,31$ & $-0,09$ \\
\hline Anos de serviço no ensino especial & 9,70 & 7,45 & 9,23 & 8,39 & 48 & 0,16 & 0,06 \\
\hline
\end{tabular}


Tabela 7. Médias, desvios-padrão e teste $t$ de diferenças de médias para os dois clusters de educadoras em variáveis de envolvimento (níveis e tipos) da criança com NEE.

\begin{tabular}{|c|c|c|c|c|c|c|c|}
\hline \multirow{3}{*}{$\frac{\text { Variáveis }}{\text { Níveis de Envolvimento }}$} & \multicolumn{4}{|c|}{ Clusters dos Educadores } & \multirow[b]{3}{*}{$d f$} & \multirow[b]{3}{*}{$t$} & \multirow[b]{3}{*}{$d$} \\
\hline & \multicolumn{2}{|c|}{$\begin{array}{l}\text { Cluster } 1 \\
(n=10)\end{array}$} & \multicolumn{2}{|c|}{$\begin{array}{l}\text { Cluster } 2 \\
(n=40)\end{array}$} & & & \\
\hline & $M$ & $D P$ & $M$ & $D P$ & & & \\
\hline Persistente & 0,17 & 0,29 & 0,26 & 0,57 & 48 & $-0,50$ & $-0,20$ \\
\hline Simbólico & 0,29 & 0,56 & 0,58 & 1,14 & 48 & $-0,78$ & $-0,32$ \\
\hline Codificado & 9,79 & 8,48 & 10,83 & 9,96 & 48 & $-0,30$ & $-0,11$ \\
\hline Construtivo & 4,38 & 4,37 & 5,91 & 6,92 & 48 & $-0,67$ & $-0,26$ \\
\hline Diferenciado & 55,83 & 12,48 & 57,68 & 13,85 & 48 & $-0,38$ & $-0,14$ \\
\hline Atenção Focalizada & 14,46 & 6,91 & 14,10 & 6,89 & 48 & 0,15 & 0,05 \\
\hline Indiferenciado & 0,25 & 0,35 & 0,14 & 0,56 & 48 & 0,61 & 0,24 \\
\hline Atenção Ocasional & 9,42 & 5,85 & 6,07 & 3,69 & 48 & $2,26^{*}$ & 0,68 \\
\hline Não envolvido & 5,42 & 5,08 & 4,40 & 7,80 & 48 & 0,39 & 0,15 \\
\hline Sofisticado & 14,63 & 12,75 & 17,58 & 15,16 & 48 & $-0,57$ & $-0,21$ \\
\hline Não Sofisticado & 9,67 & 5,95 & 6,21 & 3,68 & 48 & $2,33^{*}$ & 0,70 \\
\hline Tipos de Envolvimento & $M$ & DP & $M$ & $D P$ & $d f$ & $t$ & $d$ \\
\hline Pares & 20,25 & 10,95 & 16,93 & 10,35 & 48 & 1,04 & 0,31 \\
\hline Adultos & 39,29 & 11,99 & 44,34 & 13,86 & 48 & $-1,06$ & $-0,39$ \\
\hline Objectos & 37,54 & 13,02 & 36,31 & 14,25 & 48 & 0,25 & 0,09 \\
\hline Self & 2,92 & 3,66 & 2,93 & 4,91 & 48 & $-0,01$ & 0,0 \\
\hline Social & 59,50 & 11,30 & 60,70 & 13,80 & 48 & $-0,25$ & $-0,10$ \\
\hline
\end{tabular}

$* p<0,05 ; * * p<0,01 ; * * * p<0,001$

$d=$ Média de Cohen para o cálculo do tamanho do efeito (pequeno se $0,20<|d|<0,40$, moderado se $0,40<|d|<0,70$ e grande se $<|d| \geq 0,70)$ (Cohen, 1988; NICHD ECCRN, 2006)

\section{Discussão}

Os resultados do presente estudo indicam que as educadoras do Ensino Especial podem ser empiricamente classificadas em grupos distintos e homogéneos com base nas cotações dos seus comportamentos interactivos observados nas salas de creche e de jardim-de-infância, podendo, desse modo, contribuir para melhorar o conhecimento sobre a natureza das interacções dessas educadoras com crianças com NEE. As educadoras foram classificadas em dois grupos por meio de um procedimento de análise de clusters. Foram encontradas diferenças entre os dois grupos em medidas de qualidade de estrutura e no envolvimento das crianças com NEE que com elas interagiam nas salas regulares.

No presente estudo adoptamos uma abordagem multivariada dos padrões de relação entre comportamentos directivos, elaborativos e responsivos das educadoras na sua interacção com as crianças, abordagem realizada por de Kruif e cols. (2000) e, mais recentemente, no contexto português, por Pinto (2006). Essa abordagem conceptualiza a Directividade, o grau de Elaboração e a Responsividade como constructos multivariados existindo em contínuos separados, de tal forma que podem coexistir num mesmo padrão interactivo, com graus diversos.

Os nossos dados indicam que as educadoras manifestaram um espectro variado de comportamentos interactivos, confir- mando as conclusões de diversos estudos que indicam que a Directividade e a Responsividade não devem ser conceptualizadas como dois extremos do mesmo contínuo, devendo assumir-se que as interacções podem ser simultaneamente directivas, responsivas e elaborativas. Desse modo, no presente estudo, os clusters encontrados distinguem-se pela quantidade de directividade e de elaboração dos comportamentos interactivos das educadoras durante as suas interacções com as crianças, sendo que ambos os perfis apresentam, embora em diferentes proporções, comportamentos directivos e elaborativos.

Assim, as educadoras identificadas no primeiro cluster como sendo Directivas, eram mais frequentemente observadas a: (a) tentar parar as crianças para as levar a fazer algo diferente; (b) introduzir as crianças não envolvidas em novas actividades; (c) fornecer informação sem elaborar; e (d) mais raramente, elogiar as acções da criança. No entanto, essas educadoras apresentavam também, com alguma frequência, comportamentos elaborativos-directivos, solicitando às crianças respostas com base no seu envolvimento e eram medianamente elaborativas nas suas interacções.

As educadoras identificadas no segundo cluster como Elaborativas, eram mais frequentemente observadas a: (a) fornecer às crianças informação ou materiais de forma a elaborar as suas actividades actuais; (b) procurar desencadear 
respostas relacionadas com as actividades em que a criança estava envolvida; (c) elogiar e reconhecer as acções da criança; e (d) ser mais afectuosas. Esse último estilo interactivo foi o mais frequente na nossa amostra, sendo que $80 \%$ das educadoras foram caracterizadas como Elaborativas. Esse resultado é consistente com os verificados por de Kruif e cols. (2000) e por Pinto (2006) que também identificaram um grupo de educadores Elaborativos, caracterizados por valores elevados em comportamentos elaborativos e valores baixos em comportamentos de redireccionamento.

O número de crianças na sala, os anos de educação formal e a idade da educadora contribuíram para explicar as diferenças nos dois perfis interactivos das educadoras da amostra, indicando que as educadoras pertencentes ao cluster de educadoras Elaborativas têm mais anos de educação formal e são mais jovens. Verificaram-se ainda diferenças entre os dois grupos de educadoras relativamente ao tamanho do grupo em que as crianças com NEE estavam incluídas, sendo que as educadoras consideradas Elaborativas estavam em salas com um menor número de crianças. Não foram encontradas diferenças no número de adultos, no rácio adulto:criança, no número de anos de serviço em Educação de Infância e no Ensino Especial, resultados concordantes com os relatados por de Kruif e cols. (2000) e por Pinto (2006).

Foram encontradas diferenças entre os dois grupos relativamente ao envolvimento individual das crianças. Nas salas das educadoras Directivas, isto é, as educadoras com valores mais elevados em comportamentos de redireccionamento, as crianças passavam mais tempo em envolvimento não sofisticado, nomeadamente em comportamentos de atenção vaga e em comportamentos repetitivos. Esse resultado é consistente com estudos anteriores, em que a frequente utilização de redireccionamentos pelos educadores, estava relacionado com: (a) proporções mais baixas de envolvimento de grupo; (b) percentagens mais elevadas de comportamentos de não envolvimento (e.g., crianças desocupadas e à espera de uma nova actividade); (c) percentagens mais elevadas de comportamentos repetitivos de baixo nível (de Kruif, McWilliam \& Ridley, 2001a); de Kruif \& cols., 2000; Pinto, 2006). Nas salas com educadoras Elaborativas, as crianças têm tendência a despender mais tempo em comportamentos de envolvimento mais sofisticado, nomeadamente comportamentos de envolvimento persistente, simbólico e construtivo. Relativamente ao tipo de envolvimento, as crianças passam mais tempo em interacção com adultos e menos tempo em interacção com os pares quando comparadas com as crianças que têm educadoras Directivas. Desse modo, as educadoras Elaborativas parecem promover interacções de carácter diádico de forma a dar continuidade às actividades escolhidas pela criança. Esses resultados não vão ao encontro dos resultados verificados por Mahoney e Wheeden (1999). De facto, esses autores verificaram que a Directividade estava relacionada com maior envolvimento das crianças com o educador. Esse resultado, no presente estudo, pode dever-se ao facto de, embora as educadoras do Cluster 2 sejam essencialmente elaborativas, estas apresentam igualmente com elevada frequência um comportamento directivo-elaborativo, isto é, passam grande parte do tempo a solicitar respostas às crianças, ainda que essas solicitações sejam relacionadas com as actividades em que as crianças estão envolvidas.
Esse facto parece indicar que a educadora determina, a nível interactivo, o tipo de envolvimento da criança, não lhe fornecendo grande espaço para que esta tome iniciativas e escolha novas actividades, o que não promove a criação de oportunidades de interacção com os pares.

Em conclusão, os resultados apresentados permitem confirmar que as crianças com NEE se beneficiam de práticas e de padrões de interacções educativas essencialmente Elaborativas, embora com algum teor de Directividade. Quando comparados com padrões essencialmente Directivos, estes parecem estar mais associados à promoção de processos de aprendizagem construtivos pela criança, tais como a exploração, a persistência, a prática e a resolução de problemas. De igual modo, práticas educativas Responsivas aos interesses individuais e às capacidades das crianças devem igualmente ser promovidas de forma a potenciar níveis mais elevados de envolvimento em crianças com NEE.

Os resultados deste estudo permitem, ainda, salientar a necessidade de tornar as educadoras do Ensino Especial sensíveis a aspectos específicos da sua interacção com as crianças com NEE em salas de Educação de Infância inclusivas, nomeadamente, no sentido de promover o envolvimento da criança com os seus pares. Parece pois, ser fundamental um trabalho de parceria entre o educador do Ensino Especial e o educador do Ensino Regular, em actividade de grande e de pequeno grupo, de forma consistente e desenvolvimentalmente adequada, quer em actividades estruturadas, quer em actividades de jogo livre. Por último, os resultados encontrados parecem ter implicações práticas na formação de educadores, realçando a necessidade de: (a) transmitir aos educadores informação sobre os seus comportamentos interactivos e a relação destes comportamentos com o envolvimento das crianças, de forma a torná-los sensíveis tanto às suas interacções, como ao efeito que estas podem ter no envolvimento das crianças; (b) utilizar a EAEE não só para observação, classificação e caracterização dos comportamentos interactivos dos educadores, mas também como base para formação em serviço dos educadores; e (c) levar os educadores a monitorizar as interacções, de modo a fomentar a menor utilização de redireccionamentos e a maior utilização de elaborações.

\section{Referências}

Arnett, J. (1998). Caregivers in day-care centers: Does training matter? Journal of Applied Developmental Psychology, 10, 541552.

Bredekamp, S. (1987). Developmentally appropriate practice in early childhood programs serving children from birth through age eight (expanded ed.). Washington: National Association for the Education of Young Children.

Bredekamp, S., \& Rosegrant, T. (1996). Reaching potentials trough appropriate curriculum: Conceptual framework for applying guidelines. Em S. Bredekamp \& T. Rosegrant (Orgs.), Reaching potentials: Appropriate curriculum and assessment for young children (pp. 28-42). Washington: National Association for the Education of Young Children.

Cohen, J. (1988). Statistical power analysis for the behavioral sciences ( $2^{\mathrm{a}}$ ed.). Hillsdale: Lawrence Erlbaum Associates. 
de Kruif, R. E. L., McWilliam, R. A., \& Ridley, S. M. (2001a). Effects of child characteristics and teacher interaction behaviors on children's observed engagement. [Manuscrito não publicado]. Chapel Hill: University of North Carolina.

de Kruif, R. E. L., McWilliam, R. A., \& Ridley, S. M. (2001b). Teachers' interaction behaviors with toddlers and preschoolers [Manuscrito não publicado]. Chapel Hill: University of North Carolina.

de Kruif, R. E. L., McWilliam, R. A., Ridley, S. M., \& Wakely, M. B. (2000). Classification of teacher's interaction behaviors in early childhood classrooms. Early Childhood Research Quarterly, 15, 247-268.

de Kruif, R. E. L., Zully, R. A., McWilliam, R. A., Scarborough, A. A., \& Sloper, K. M. (1998). Cases of responsiveness and directivenesss and different levels of teaching. [Manuscrito não publicado]. Chapel Hill: University of North Carolina.

Howes, C., \& Stewart, P. (1987). Child's play with adults, toys, and peers: An examination of family and child-care influences. Developmental Psychology, 23, 423-430.

Landis, J. R., \& Koch, G. G. (1977). The measurement of observer agreement for categorical data. Biometrics, 33, 159-174.

Mahoney, G., \& Wheeden, C. A (1999). The effect of teacher style on interactive engagement of preschool-aged children with special needs. Early Childhood Research Quarterly, 14, 51-68.

McWilliam, R. A., \& de Kruif, R. E. L. (1998). Engagement Quality Observation System III (E-Qual III). Chapel Hill: Frank Porter Graham Child Development Center, University of North Carolina.

McWilliam, R. A., Scarborough, A. A, Bagby, J., \& Sweeney, A. (1998). Teaching Styles Ratting Scales (TSRS). Chapel Hill: Franck Porter Graham Child Development Center, University of North Carolina.
National Association for Education of Young Children NAEYC (1997). Developmentally appropriate practice in early childhood programs serving children from birth trough age 8: A position statement of the National Association for the Education of Young Children. Washington: NAEYC.

NICHD Early Child Care Research Network (2006). Child care effect sizes for the NICHD study of early child care and youth development. American Psychologist, 2, 99-116.

Phillips, D. A., McCartney, K., \& Scarr, S. (1987). Child care quality and children's social development. Developmental Psychology, 23, 537-543.

Pinto, A. I. (2006). O envolvimento da criança em contexto de creche: os efeitos de características da criança, da qualidade do contexto e das interacções educativas. Tese de Doutorado, Universidade do Porto, Porto.

Raspa, M. J., McWilliam, R. A., \& Ridley, S. M. (2001). Child care quality and children's engagement. Early Education and Development, 12, 209-224.

Simeonsson, R. J., \& Bailey, D. B. (1991). ABILITIES Index. Chapel Hill: Frank Porter Graham Development Center, University of North Carolina.
Recebido em 30.07.08

Primeira decisão editorial em 23.10.08

Versão final em 02.02.09

Aceito em 17.03.09 